\title{
ANALISIS TINGKAT KEPATUHAN PASIEN TBC RAWAT JALAN TERHADAP PENGGUNAAN OBAT ANTI TUBERKULOSIS DI PUSKESMAS SINDAR RAYA
}

\author{
1) Supartiningsih, ${ }^{2)}$ Rd. Siti Riski Ainun \\ ${ }^{1,2)}$ Program Studi S1Farmasi Fakultas Farmasi dan Ilmu Kesehatan Universitas Sari Mutiara Indonesia \\ ${ }^{1,2} \mathrm{Jl}$. Kapten Muslim No.79, Helvetia Tengah, Kec. Medan Helvetia, Kota Medan, Sumatera Utara \\ E-Mail :nigsih.ndy@gmail.com,rd.siti.riski.ainun99@gmail.com
}

\begin{abstract}
ABSTRAK
Kurangnya kepatuhan dalam meminum obat anti tuberculosis mengakibatkan kejadian tuberkulosis pada paru yang sangat tinggi dan sulit diturunka. Hal ini di akibatkan kurangnya pengetahuan dan dorongan dari keluarga menjadi penyebab yang dapat mempengaruhi tingkat kepatuhan pasien untuk meminum obat anti tuberkulosis. Tujuan Pengabdian ini melihat gambaran kepatuhan pasien dan melihat bagaimana hubungan pengetahuan dan dukungan keluarga terhadap kepatuahan pasien TBC rawat jalan dalam meminum obat anti tuberkulosis di Puskesmas Sindar Raya. Jenis pengabdi kuantitatif dengan menggunakan pendekatan Cross Sectional pada 20 responden. Cara pengmbilan sampel dengan teknk total sampling. Pungumpulan data dengan cara memberikan kuisioner kepadamasing masing responden. Analisi data yang digunakan menggunakan analisa univariat dan uji Chi Square pada analisis bivariat. Hasil pengabdian univariat menunjukan tingkat pengetahuan yang baik sebanyak 10 responden $(50,0 \%)$, cukup 8 responden $(40,0 \%)$, dan kurang 2 responden $(10,0 \%)$. Dukungan keluarga yang baik sebanyak 9 responden $(45,0 \%)$, cukup 5 responden $(25,0 \%)$, dan kurang 6 responden ( $30,0 \%)$. Tingkat kepatuhan kategori patuh berjumlah 15 responden $(75,0 \%)$ dan tidak patuh 5 responden $(25,0 \%)$. Berdasarkan analisis bivariate dengan uji Chi Square menujukan adanya hubungan yang antara pengetahuan dengan kepatuhan meminum obat anti tuberkulasis $(P$ value $=0,036)$, dan juga adanya hubungan bermakna antara dorongan keluarga dengan kepatuhan meminum obat anti tuberkulosis ( $\mathrm{P}$ value $=0,017$ )
\end{abstract}

Kata Kunci : Tuberkulosis, Tuberkulosis, Pengetahuan, Dorongan Keluarga, Kepatuhan Meminum Obat

\begin{abstract}
The incidence of pulmonary tuberculosis is still very high and difficult to reduce due to the lack of compliance in talking anti-tuberculosis drugs. The lack ofknowledge and family support are some of the factorsthat affect the level of patients' compliancein taking anti-tuberculosis drugs. The purpose of this study is tohave overview of patients' compliance and to see how the relationship between knowledge and family support can affect TB outpatients in taking anti- tuberculosis drugs at the Sindar Raya Community Health. This type of research is quantitative using a cross-sectional approach to 20 respondents who do outpatient treatment at the Sindar Raya Community Center. The sampling technique. The data collecting is done by giving questionnaires to each respondent. The data analysis uses univariate analysis and Chi Square test on bivariate analysis. The results of the univariate research showed that there were 10 respondents (50.0\%) with a good level of knowledge,8 respondents (40.0\%) with moderate level knowledge, and 2 respondents (10.0\%) with the lack of knowledge. Good family support showed as many as 9 respondents (45.0\%), 5 respondents (25.0\%) with moderate support, and6 respondents (30.0\%) with lack of support. As many as 15 respondents (75.0\%) showed a good level of compliance while 5 respondents (25.0\%) showed the lack of compliance level. Based on bivariate analysis with the Chi Square test, there was a singnificant relationship between knowledge and compliance to taking anti-tuberculosis drugs ( $P$ value $=0.036)$, and there was also a significant relationship between family support and compliance to taking anti-tuberculosis drugs ( $P$ value $=0.017)$.
\end{abstract}

Keyword: Tuberculosis, Knowledge, Family Support, Drug Compliace

\section{PENDAHULUAN \\ Latar Belakang}

Masalah kesehatan masyarakat di negara-negara berkembang sangat identik dengan masalah kesehatan yang berhubungan dengan masalah ekonomi dan sanitasi salah satunya adalah penyakit tuberkulosis. Penyakit tuberkulosis adalah penyakit yang menular yang bersifat kronis dan sangat cepat menular. Diperkirakan kurang lebih sepertiga penduduk didunia sudah terinfeksi akibat Mycobacterium Tuberkulosis. Sekitar tahun 1995 diperkirakan 9 juta pasien TBC dan 3 juta kematian akibat TBC di seluruh duina mencapai 95\% kasus dan 98\% kematian yang 
diakibatkan penyakit TBC di seluruh dunia yang terjadi di negara-negara berkembang, demikian juga angka kematian pada wanita dikarenakan TBC lebih banyak dari kematian yang dikarenakan kehamilan, persalinan dan nifas [1].

Pulmonary TB umumnya menyerang paru- paru dikaibatkan oleh kuman Tuberculosis sehingga lebih dikenal dengan nama TBC atau TB. Akibat lain yang disebabkan oleh kuman tuberculosis adalah penyebaran ke bagian/organ lain dalam tubuh, dan tuberculosis jenis ini lebih berbahaya dari pulmonary TB. Apabila kuman tuberculosis menyerang otak dan sistem saraf pusat maka dapat menyebabkan meninggal dunia. Oleh karena itu kuman tuberculosis diindikasi dapat menginfeksi hampir seluruh organ tubuh, seperti ginjal, jantung, saluran kencing, tulang, sendi, otot, usus, kulit, disebut miliary TB atau extrapulmonary TB [2].

Penyebab utama sulitnya Insiden tuberculosis paru ini diturunkan adalah karena masalah non medik seperti:, keadaan gizi yang rendah, kemiskinan, hygiene yang rendah, daya beli rendah, pendidikan rendah menyebabkan kegagalan dan keterlambatan dalam mendapatkan diagnosis hal ini juga disebabkan sulitnya jangkaun fasilitas kesehatan pada daerah terpencil. Solusi yang sudah dilakukan dalam upaya pencegahan TBC antara lain dengan melakukan kunjungan secara rutin ke rumah masyarakat guna memastikan bahwa tempat tinggal mereka memiliki sanitasi yang baik sesuai dengan standar kesehatan yangditetapkan. Selain itu sosialisasi secara berkala mengenai pentingnya lingkungan yang sehat harus terus digalakkan kepada masyarakat sehingga mereka memahami pentingnya pola hidup sehat. [3].

Semenjak tahun 1995 pemberantasan TBC sudah dilakukan dengan program strategi DOTS (Directly Treatment Shortcourse Chemoterapy) yang direkomendasikan oleh WHO. Menurut WHO cara yang paling efektif memberantas penyakit TBC adalah dengan menghentikan tuberkulosis pada sumbernya yang dikenal dengan strategi stop at the source dengan pengobatan tuberculosis menggunakan strategi DOTS. Prevalensi yang besar tetapi cakupan stategi pengobatan DOTS masih rendah apalagi disertai banyak penderita yang putus berobat (drop out) menyebabkan kemungkinan penularan masih tetap tinggi hal ini juga disebabkan kurang pemahaman mengenai gejala yang ditimbulkan seperti demam, lemas, berat badan turun, tidak nafsu makan, nyeri dada dan berkeringat dimalam hari. [4].

Adapun salah satu upaya pengendalian dengan strategi telah diterapkan di banyak negara berlembang sejak tahun 1995 adalah Directly Observed Treatment Shortcourse (DOTS) akan tetapi TBC tetap menjadi masalah terbesar bagi dunia karena lemahnya ekonomi pasien pada daerah yang banyak terkena TBC. Pasien TBC lebih banyak terjangkit pada kelompok usia produktif secara ekonomi (15-50 tahun) dengan presentasi sebesar 75\%. Pasien TBC dewasa akan kesulitan untuk bekerja dikarenakan tidak ada tenaga sehingga kehilangan rata-rata waktu untuk bekerja selama 3-4 bulan yang mengakibatkan kerugian secara ekonomis. Selain itu, pasien TBC juga mendapatkan dampak negative lainnya secara sosial, yaitu akan diasingkan dan dikucilkan oleh masyarakat [5].

Penyebab utama yang mempengaruhi peningkatan angka penderita TBC antara lain ialah kondisi sosial ekonomi yang menurun pada berbagai kelompok masyarakat, yaitu kurang terpenuhinya status gizi, kondisi lingkungan dalam dan luar rumah yang kurang bersih sangat mendukung terjadinya penyakit tuberculosis, perubahan demografi karena meningkatnya penduduk yaitu wilayah dengan kepadatan yang cukup tinggi, kurang memadainya tata laksana dan belum optimalnya pelaksanaanprogram penanggulangan TBC [6].

Berdasarkan hasil wawancara dengan 6 pasien TBC yang di lakukan di Puskesmas Sindar Raya pada bulan Juli 2020, terdapat 4 orang yang tidak mengetahui bagaimana penularan penyakit TBC ini terjadi. Beberapa pasien ada yang di dampingi keluarga dan ada yang datang seorang diri, menurut 2 pasien yang datang seorang diri, dirinya tidak diperhatikan keluarga karna penyakit yang diderita bahkan di kucilkan.

Dari latar belakang di atas untuk mengetahui seberapa besar pengetahuan pasien tentang penyakitnya dan bagaimana dukungan keluarga pasien. Apakah dengan pengetahuan yang baik 
dan dukungan keluarga dapat mempengaruhi pasien menjadi patuh meminum obatnya, mengingat TBC merupakan penyakit yang rentan menular sehingga dibutuhkan kepatuhan dalam proses pengobatan TBC yang merupakan faktor terpenting untuk di teliti sehingga diharapkan melalui pengabdian masyarakat akan memperoleh gambaran mengenai sikap disiplin pasien untuk melakukan pengobatan secara berkala pada penderita TBC dan untuk mengetahui faktorfaktor yang mempengaruhi tingkat kepatuhan pasien TB paru dalam meminum obat di Puskesmas Sindar Raya.

\section{METODE PELAKSANAAN}

Pelaksanaan kegiatan pengabdian ini dilakukan dalam bentuk workshop dengan kerangka konsep pada gambar 1.1 sebagai berikut :

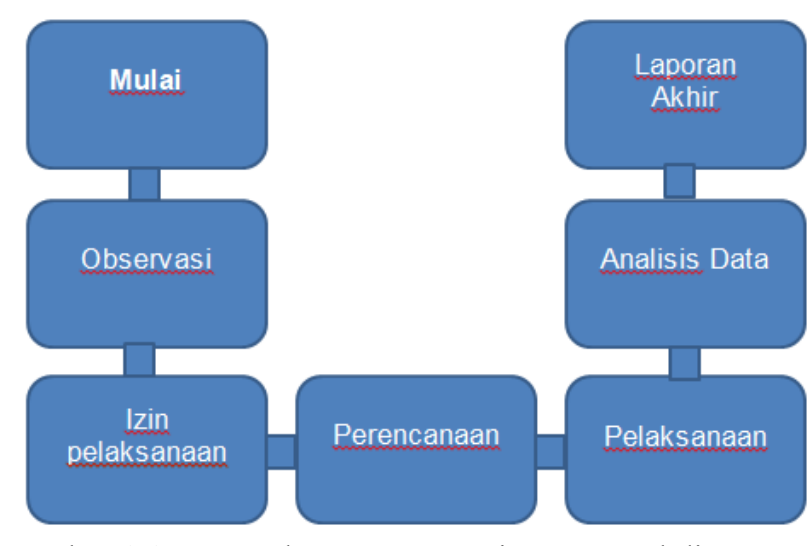

Gambar 1.1. Kerangka Konsep Kegiatan Pengabdian

Pengabdi dilaksanakan di Puskesmas Sindar Raya. Pengabdian dilaksanakan di bulan Juli sampai Agustus tahun 2020, pada Pengabdian ini sampel yang digunakan adalah pasien Tuberkulosis (TBC) rawat jalan di Puskesmas Sindar Raya. Pengabdian ini menggunakan semua populasi (total sampling) .Jumlah sampling 20 orang Teknik Pengumpulan data dengan cara wawancara.

\section{Aspek Pengukuran Data}

1. Kepatuhan Meminum Obat
a. Patuh
: Jika mendapat skor 0
b. Tidak Patuh: Jika medapat skor 1-9

2. Pengetahuan
a. Nilai $15-20$ untuk mejawab kuisioner termasuk dalam kategori Baik
b. Nilai 11 - 14 untuk menjawab kuisioner termasuk dalam kategori Cukup
c. Nilai $<10$ untuk menjawab kuisioner termasuk dalam kategori Kurang

3. Dorongan Keluarga

a. Jika responden mendapat nilai $8-10$ dalam menjawab kuisioner termasuk kategori Baik

b. Jika responden mendapat nilai 5- 7 dalam menjawab kuisioner termasuk kategori Cukup

c. Jika responden mendapat nilai $<4$ dalam menjawab kuisioner termasuk kategori Kurang 


\section{Pengolahan Data}
a. Editing (Pengecekan)
b. Coding (kode)
c. Entry Data
d. Tabulating (Tabel)

\section{Analisis Data}

a. Univariat adalah bertujuan menganalisis tiap variabel dari hasil Pengabdi

b. Bivariat adalah untuk menguji ada dan tidaknya pengaruh antara variable

\section{HASIL}

Karakteristik responden yaang meliputi jenis kelamin laki - laki yang memiliki aktifitas lebih tinggi jika dibandingkan dengan jenis kelamin perempuan, sehingga akibatnya adalah kemungkinan lebih besar terpapar dibandingkan dengan perempuan. Selain itu kebiasaan seperti merokok dan mengkonsumsi alcohol pada laki - laki dapat menurunkan daya tahan tubuh yang menyebabkan lebih rentan terkena penyakit TB Paru.

Di Indonesia saat ini terdapat pasien penderita tuberculosis semakin meningkat yang banyak terdapat pada golongan usia produktif, terutama pada golongan usia 25 - 34 tahun dengan tingkat pendidikan yang cukup, dilingkungan kerja Puskesmas Sindar Raya menunjukkan bahwa penduduk untuk tingkat pendidikan SLTA terdapat jumlah yang paling besar. Sebagian besar responden penelitian ini adalah para petani hal ini dikarenakan sebagian besar penduduk sekitar hidup dengan cara bercocok tanam.

Tuberkulosis biasanya menyerang orang-orang yang masih berada pada ekonomi menengah seperti tunawisma, pengangguran dan fakir miskin. Hal ini sudah sesuai dengan hasil penelitian yang dilakukan, ini menggambarkan keadaan ekonomi pasien tuberkulosis masih sangat rendah.

\section{A. Analisa Univariat}

Hasil evaluasi setelah dilakukan Pengabdian mengenai Analisis Tingkat Kepatuhan Pasien TBC Rawat Jalan Terhadap Penggunaan Obat Anti Tuberkulosis di Puskesmas sindar Raya maka diperoleh hasil :

1. Pengetauhuan

Tabel pengetahuan pasien TBC rawat jalan terhadap penggunaan obat antituberkulosis di Puskesmas Sindar Raya

Tabel 1. Tabel Hasil Kuisioner Pengetahuan

\begin{tabular}{llcc}
\hline NO & PENGETAHUAN & F & \% \\
\hline 1. & BAIK & 10 & $50,0 \%$ \\
\hline 2. & CUKUP & 8 & $40,0 \%$ \\
\hline 3. & KURANG & 2 & $10,0 \%$ \\
\hline & TOTAL & $\mathbf{2 0}$ & $\mathbf{1 0 0 , 0} \%$ \\
\hline
\end{tabular}

2. Dukungan Keluarga

Tabel dukungan keluarga pasien TBC rawat jalan terhadap penggunaan obatanti tuberkulosis di Puskesmas Sindar Raya.

Tabel 2. Tabel Hasil Kuisioner Dukungan Keluarga

\begin{tabular}{llcc}
\hline NO & DUKUNGAN KELUARGA & F & \% \\
\hline 1 & BAIK & 9 & $45,0 \%$ \\
\hline
\end{tabular}




\begin{tabular}{llcc}
\hline 2 & CUKUP & 5 & $25,0 \%$ \\
\hline 3 & KURANG & 6 & $30,0 \%$ \\
\hline & TOTAL & $\mathbf{2 0}$ & $\mathbf{1 0 0 , 0} \%$ \\
\hline
\end{tabular}

3. Kepatuhan

Tabel kepatuhan pasien TBC rawat jalan terhadap penggunaan obat antituberkulosis di Puskesmas Sindar Raya.

Tabel 3. Tabel Hasil Kuisioner Kepatuhan

\begin{tabular}{llcc}
\hline NO & KEPATUHAN & F & \% \\
\hline 1. & PATUH & 15 & $75,0 \%$ \\
\hline 2. & TIDAK PATUH & 5 & $25,0 \%$ \\
\hline & TOTAL & $\mathbf{2 0}$ & $\mathbf{1 0 0 , 0} \%$ \\
\hline
\end{tabular}

\section{B. Analisa Bivariat}

Hasil data Pengabdian di analisis menggunakan uji Chi Square, keterkaitan antara hubungan variabel independen dengan variabel dependen dengan batas perhitungan statistik $p$ value $(0,05)$, maka diperoleh hasil sebagai berikut :

1. Hubungan pengetahuan dan kepatuhan pasien TBC rawat jalan terhadap penggunaan obat Anti Tuberkulosis di Puskesmas Sindar Raya.

Tabel 4. Hubungan Pengetahuan dan Kepatuhan

\begin{tabular}{|c|c|c|c|c|c|}
\hline \multirow[b]{2}{*}{ No } & \multirow[b]{2}{*}{ Pengetahuan } & \multicolumn{3}{|c|}{ Kepatuhan Meminum Obat } & \multirow[b]{2}{*}{$\mathrm{p}$-value } \\
\hline & & Patuh & Tidak Patuh & Total & \\
\hline & & $\mathrm{F}$ & $\mathrm{F}$ & $\mathrm{F}$ & \multirow{4}{*}{0,036} \\
\hline 1 & Baik & 10 & 0 & 10 & \\
\hline 2 & Cukup & 4 & 4 & 8 & \\
\hline 3 & Kurang & 1 & 1 & 2 & \\
\hline & Total & 15 & 5 & 20 & \\
\hline
\end{tabular}

2. Hubungan dorongan dengan kepatuhan pasien TBC Rawat Jalan TerhadapPenggunaan Obat Anti Tuberkulosis di Puskesmas Sindar Raya.

Tabel 5. Hubungan dorongan keluarha dengan kepatuhan

\begin{tabular}{|c|c|c|c|c|c|}
\hline \multirow[b]{2}{*}{ No } & \multirow{2}{*}{$\begin{array}{l}\text { Dukungan } \\
\text { Keluarga }\end{array}$} & \multicolumn{3}{|c|}{ Kepatuhan Meminum Obat } & \multirow[b]{2}{*}{$\begin{array}{l}\mathrm{p}- \\
\text { value }\end{array}$} \\
\hline & & Patuh & Tidak Patuh & Total & \\
\hline & & $\mathrm{F}$ & $\mathrm{F}$ & $\mathrm{F}$ & \multirow{4}{*}{0,017} \\
\hline 1 & Baik & 8 & 1 & 9 & \\
\hline 2 & Cukup & 5 & 0 & 5 & \\
\hline & & & 204 & & \\
\hline
\end{tabular}




\begin{tabular}{ccccc}
\hline 3 & Kurang & 2 & 4 & 6 \\
\hline & Total & 15 & 5 & 20 \\
\hline
\end{tabular}

\section{Dokumentasi Kegiatan}

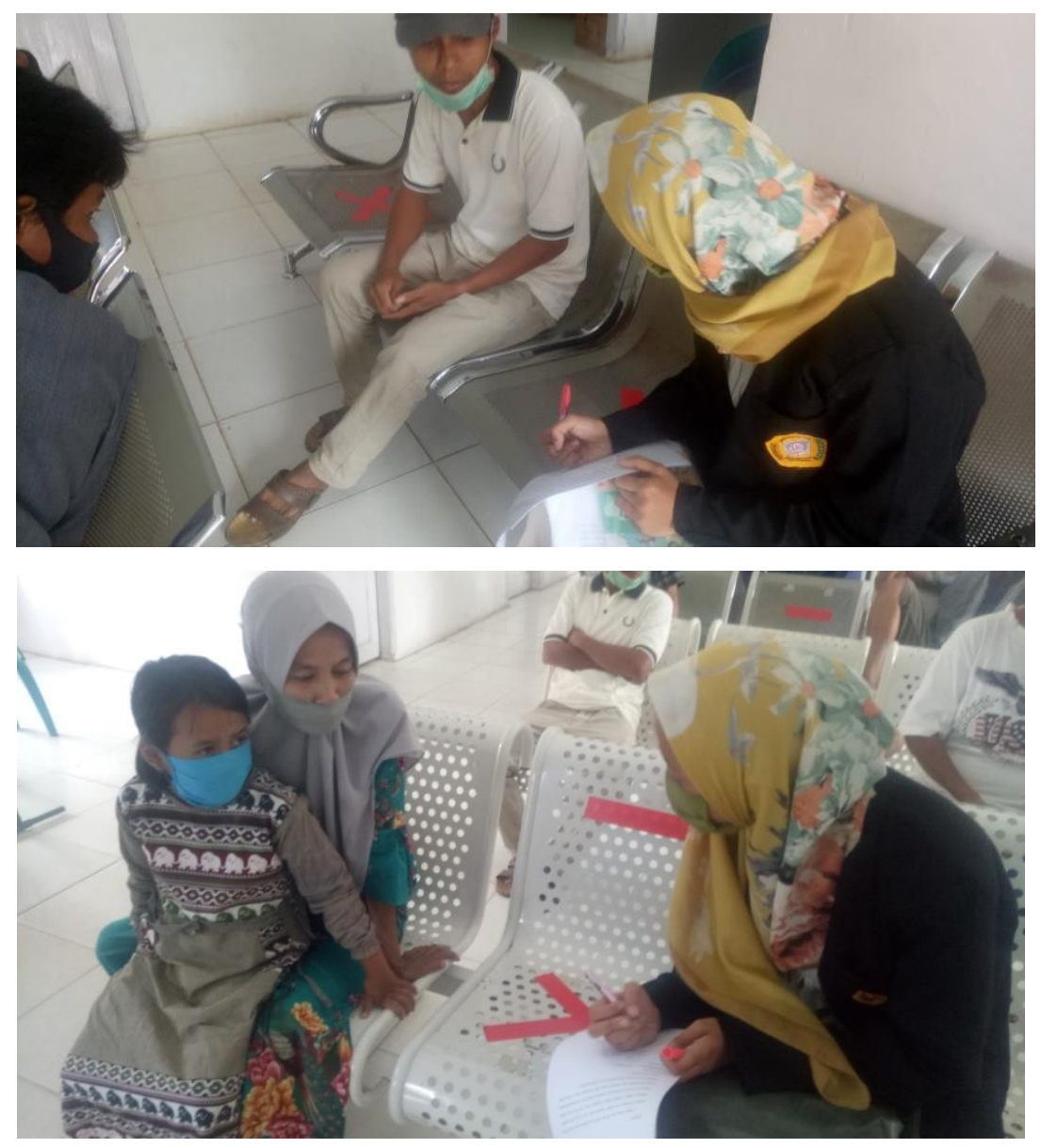

Gambar 2 Wawancara Pengabdian

\section{KESIMPULAN}

Kegiatan pengabdian yang dilakukan pada 20 responden diantaranya laki laki 15 responden $(75,0 \%)$ dan perempuan 5 responden $(15,0 \%)$ mengenai tingkat kepatuhan pasien TBC rawat jalan terhadap penggunaan obat anti tuberkulosis di Puskesmas Sindar Raya, dapat disimpulkan antara lain :

1. Berdasarkan uji hasil pengabdian yang sudah dilaksanakan, terdapat hubungan kepatuhan terhadap pasien TBC dalammeminum obat anti tuberkulosis di Puskesmas Sindar Raya sebanyak 15 responden $(75,0 \%)$ patuh ,sedangkan sebanyak 5 responden $(15,0 \%)$ tidak patuh.

2. Bedasarkan uji hasil pengabdian yang dilakukan terdapat bahwah hubungan antara pengetahuan terdapat tingkat kepatuhan meminum obat anti tuber kulosis $(p=0,036)$

3. Dari uji hasil Pengabdian yang telah dilaksanakan, terdapat hubungan antaradukungan keluarga terhadap tingkat kepatuhan meminum obat anti tuberkulosis dengan $(p=0,017)$ 


\section{DAFTAR PUSTAKA}

[1] Depkes RI. 2015. Pharmaceutical Care Untuk Penyakit Tuberkulosis, Direktorat Bina Farmasi Dan Klinik Direktorat Jenderal Bina Kefarmasian Dan Alat Kesehatan.

[2] Desmulyati. 2015. Diagnosa Penyakit Tuberculosis (TBC) Menggunakan Sistem Neuro Fuzzy. Jurnal Techno Nusa Mandiri. 12(2) : 97-108.

[3] K, B. 2019. Faktor Yang Mempengaruhi Tingkat Kegagalan Pengobatan Pasien Tuberkulosis (TB) Paru Pada Anak Di Puskesmas Kota Makasar. Jurnal Ilmiah Kesehatan Diagnosis. 13(6) : 680-685.

[4] Musyarofah., Rosiana., dan Siswanti. 2013. Perbedaan Kepatuhan Minum Obat Sebelum Dan Sesudah Afirmasi Positif Pada Penderita TB Paru di Puskesmas Gribig Kabupaaten Kudus. JIKK. 4(2) : 59-69.

[5] Irnawati, N. M., Iyone, E. T. S., Ronal, I., dan Ottay. 2016. Pengaruh Dukungan Keluarga Terhadap Kepatuhan Minum Obat Pada Penderita Tuberkulosis di Puskesmas Motoboi Kecil Kota Kotamobagu. Jurnal Kesehatan Komunitas dan Tropik. 4(1) : 59-64.

[6] Faradis, N. A.., dan Sofwan, I. 2018. Implementasi Kebijakan Permenkes Nomor 67 Tahun 2016 Tentang Penanggulangan Tuberkulosis. Higeia Journal Of Public Health Research AndDevelopment. 2(2) : 307-319.

[7] Widiyanto, A. 2016. Hubungan Kepatuhan Minum Obat Dengan Kesembuhan Pasien Tuberkulosis Paru BTA Positif di Puskesmas Delanggu Kabupaten Klaten. Jurnal TerpaduIlmu Kesehatan. 6(1) : 01-11 